The excess of indican is perhaps more directly due to altered nervous influence, for I have repeatedly found it in the urine of patients who had passed through the collapse stage of cholera or were suffering from certain diseases of the spinal cord.

My own opinion is, that the change of colour in Addison's disease is undoubtedly produced, like the constitutional symptoms, through the medium of the nervous system. The paling of the discolouration coincidently with remissions of the constitutional symptoms, and its deepening and extension with every fresh exacerbation of the illness, appear to me to afford strong clinical evidence that these two features of the disease are referable to a common cause. Moreover, the interesting cases, detailed by Meissner and others, of general and permanent darkening of skin produced by agony of mind, sudden alarms, and other violent emotions, leave no doubt of the fact that nervous influences are capable of producing abnormal pigmentation; and this fact seems to me to furnish another strong presumption that the progressive discolouration of the skin in Addison's disease is due to a morbid action of the affected nerves. There is, however, no evidence to connect it directly with any of the nerves actually involved in the inflammatory process, and $I$ am inclined to attribute it rather to reflex irritation through the cerebro-spinal nervous system.

Although the correctness of these inferences is not susceptible of proof, without much clearer knowledge than we now possess of the part actually played by the nerves in the physiological processes disturbed by the disease, I venture to think that the views I entertain derive considerable support from the clinical and pathological facts upon which they are based.

\section{SUCCESSFUL SERIES OF OPERATIONS FOR STONE IN THE ADULT; ILLUSTRATED BY A HUNDRED RECENT CASES.}

By SiR HENRY THOMPSON,

SURGEON-EXTRAORDINARY TO H M. THE KING OF THE BELGIANS; LATH PROTRSSOR OF CLINICAL SURGERT, AND SURGEON TO DNIFERSITY COLLTEE HOSPITAL.

THere is a famous series of stone operations which is very frequently referred to as perhaps the most successful on record, performed by Martineau, of Norwich, and reported in the Medical and Chirurgical Transactions, vol. xi., p. 402,1821 . The number of patients was 84 ; amongst whom there were only 2 deaths. The operation was, of course, in all lithotomy. They occurred between 1804 and 1820 inclusive-a period of seventeen years.

Before making any comparison with this, it will be necessary, first, to analyse briefly the list with reference to sex and age. It will then be noted that a very large proportion were children, while 6 were females; deducting these latter, there remain 78 male cases, of which not less than 34 were under 15 years of age, leaving only 44 adults. Of these 44 adults, no more than 12 were upwards of 60 years of age ; only 24 were 50 years old and upwards, giving for the latter a mean age of $62 \frac{1}{2}$ years; the 2 deaths occurred among them.

No error is more common than that of comparing lists of cases without noting this most important element of age. Death after lithotomy in children is notoriously infrequent; indeed, it is a result scarcely to be expected, unless under circumstances of some rarity. During middle life, also, lithotomy is a very successful operation; but at the age of 60 and upwards it is one of considerable risk. Hence, unless an exact statement respecting the patient's age is afforded, no inference can be drawn from any number of cases of which the results are reported. A mere statement of the number of patients operated on, with the proportion of recoveries and deaths, is absolutely valueless, and is often misleading.

I wish now to compare with the above a series of my own, and shall take for that purpose simply my last 100 cases, as a round number easily dealt with, of operation in the adult. $I$ bave not included in my list any patient below 22 years of age, at which there happens to be one. There are, indeed, only four patients, including that one, below 50 years of age, while in Martineau's series of 84 there are not less than fifty-four below that age. Of my 100 cases, sixtyfive, are above 60 years of age (only twelve are above that age in Martineau's list), and the mean age of the entire 100 cases is not less than 631 years (the mean of Martineau's entire adult series is under 47 years); consequently the age ranges far higher in my series than in his.

My present 100 cases commenced shortly before Christmas, 1872, and includes every one operated on by myself up to the present time; it consequently represents my entire work of the last two years and a quarter. It may be worth while naming, in order to show that I have not carefully selected the tern, that it commences just before the death of the late Emperor Napoleon, which is the third case of the series.

Ninety-six were adult males, four were adult females.

Of the 96 males, 87 were operated on by lithotrity and 9 by Jateral lithotomy.

The mean age of the 87 operated on by lithotrity is 63 years, the oldest being 83 , the youngest 22 , but only 4 were below 50 years.

The mean age of the 9 operated on by lithotomy was $63 \frac{1}{2}$ years also, their respective ages being $36,59,59,61,63,70$, 75 , and 79 .

Among the 87 operated on by lithotrity were 4 deaths, the ages were $61,65,66$, and 81 .

Among the 9 operated on by lithotomy were 2 deathsviz., at 61 and 63 .

Thus it will be seen that there was a total of 6 deaths in 96 patients, with a mean age of $63 \frac{1}{2}$, by the two operations. While alluding to what has been termed a run of successful cases in practice, I may observe that in this 100 of mine there was one more remarkable than I have ever before witnessed or heard of. I had a succession of 51 elderly adult cases witbout a single death. They occurred between July, 1873, and June, 1874. These 51 cases (7 more than Martineau's entire adult series of all ages) had a mean age of 64 vears.

I wish to present this brief résumé as a fair example of what careful selection of the two operations is now capable of accomplishing for calculous patients. It is a little better than my entire average, including all my earliest experiences. What that is I hope scon to give to the profession in a complete form. I hope then to have the opportunity of recording all that $I$ have been able to glean from an unbroken series of 500 cases in the adult male, besides the cases of women and children.

Wimpole-street, $W$.

\section{PULSATILE FLUSHING OR REDDENING OF THE PALMS OF THE HANDS AND VENOUS PULSATION.*}

BY W. H. BROA DBENT, M.D., F.R.C.P.,

PHYSICIAN TO ST. MARX'S HOSPITAL AND THE IONDON FETER HOSPITAZ.

Sxmptoms are met with from time to time which it is worth while to detach from the case in which they are observed, and consider separately and independently, either on account of their rarity or from some special significance which attaches to them, or from their bearing on the general relations of disease.

Such a symptom is pulsatile flushing of the cutaneous capillaries, which has twice come under my notice lately. It is most readily seen, according to my experience, in the hands when they are warm from having been under the bedelothes, and on their palmar aspect. In the cases in which it is observed certain parts of the palm will be found to present a bright pink blush, the prominences, namely, along the series of metacarpo-phalangeal joints, the thenar and bypothenar eminences, but notably the ball of the first finger. Fixing the attention on any of these points, but especially on the part last named, the redness is seen suddenly to extend and deepen with each pulsation of the arteries, fading rather less quickly in the interval. In a well-marked case these rapid alternations of red and white have almost a

* By venous pulsation is meant, not reflex jugular pulsation, but direct *. By venous pulsation is meant, not reflex $j$
pulsation in the veins on the back of the hand. 